$\mathrm{DE}$

M E D I C I N A

T R O P I C A L

$\mathrm{DE}$

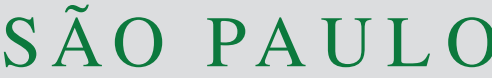

JOURNAL OF THE SÃO PAULO INSTITUTE OF TROPICAL MEDICINE

1'Instituto Adolfo Lutz, Laboratório de Patologia, São Paulo, São Paulo, Brazil

${ }^{2}$ Instituto Butantan, Laboratório de Bacteriologia, São Paulo, São Paulo, Brazil

${ }^{3}$ Universidade de São Paulo, Hospital das Clínicas, Departamento de Nefrologia, Laboratório de Investigação Médica (LIM-12), São Paulo, São Paulo, Brazil

${ }^{4}$ Universidade de São Paulo, Instituto de Medicina Tropical de São Paulo, São Paulo, São Paulo, Brazil

tin memoriam

Correspondence to: Patrícia Antonia Estima Abreu

Instituto Butantan, Laboratório de Bacteriologia, Avenida Vital Brasil, 1500, Butantã, CEP 05503-900, São Paulo, SP, Brazil

Tel: +55 11 99278-2829

E-mail: patricia.aniz@ butantan.gov.br

Received: 22 June 2020

Accepted: 13 October 2020

\section{Immunohistochemical detection of Lp25 and LipL32 proteins in skeletal and cardiac muscles of fatal human leptospirosis}

\author{
Silvia D'Andretta Iglezias', Patrícia Antonia Estima Abreu ${ }^{(12}$, \\ Cristina Kanamura ${ }^{\circledR}$, Antonio José Magaldi ${ }^{3}$, Antonio Carlos Seguro ${ }^{3}$, \\ Thales De Brito ${ }^{4+}$
}

\section{ABSTRACT}

Leptospirosis is an acute infection caused by pathogenic species of the genus Leptospira, which affects humans and animals in all world. In severe forms of the disease, kidneys, liver and lungs are the main affected organs, resulting in acute kidney injury, jaundice and pulmonary hemorrhage. Previous post-mortem studies have shown that lesions are not limited to these organs. Cardiac and striated muscle injuries have already been reported, but the pathophysiology of cardiac and skeletal lesions in leptospirosis is not fully understood. It has been suggested that the tissue damage observed in leptospirosis could be directly mediated by leptospires or by their toxic cellular components. LipL32 and Lp25 are leptospira membrane proteins with unknown functions, that are present only in pathogenic strains of Leptospira spp. Both proteins induce skeletal muscle lesions similar to those observed when normal guinea pigs are inoculated with leptospires. Through immunohistochemistry, this study showed the presence of LipL32 and Lp25 proteins on muscle cell membranes and in the underlying cytoplasm of skeletal muscles, as well as focal lesions in cardiac tissues of fatal cases of leptospirosis. Altogether, these results reinforce that both proteins can be important factors in the pathogenesis of leptospirosis.

KEYWORDS: Leptospira. Leptospirosis. Rhabdomyolysis. Weil's disease. Lp25. LipL32.

\section{INTRODUCTION}

Leptospirosis is an acute bacterial septicemic disease caused by pathogenic species of the genus Leptospira, affecting humans and animals in all world ${ }^{1}$. It is a zoonosis associated with chronically infected carrier animals, especially rodents. In humans, leptospirosis has a biphasic clinical presentation, which begins with the septicemic phase followed by immune manifestations ${ }^{2}$. At least 80 to $90 \%$ of cases are either asymptomatic or exhibit a non-specific self-limited febrile disease. However, 5 to $10 \%$ of cases manifest the most severe form of the disease (Weil's syndrome or severe pulmonary hemorrhage syndrome) with multisystemic damage including vascular, hepatic, renal and pulmonary manifestations ${ }^{2-4}$. Striated muscle injury is frequent and remarkable in leptospirosis ${ }^{5-7}$. Myalgia has been reported on $92.5 \%$ of patients with leptospirosis and it may be an early symptomatology of the disease ${ }^{6}$.

Rhabdomyolysis is an acute clinicopathological syndrome that results from the necrosis of striated muscle leading to the release of intracellular contents such as myoglobin, electrolytes and enzymes into the bloodstream ${ }^{8}$. Clinically, it is a proximal myopathy with myalgia and creatine kinase (CK) levels greater than 
$1,000 \mathrm{U} / \mathrm{L}$. The pathological features are isolated fiber necrosis, myopathic changes and regeneration, as well as focal inflammatory changes with some macrophage activity $^{9}$. Complications also include acute kidney injury, which is also very common in severe leptospirosis?

Muscle injury may result from multiple causes like a direct pathogen invasion, tissue hypoxia, high lysosomal enzymatic activity, or the release of toxins ${ }^{8}$. In leptospirosis, rhabdomyolysis is present in up to $62 \%$ of patients and this condition is detected by high CK levels in the bloodstream ${ }^{10}$.

The skeletal muscle lesions of leptospirosis are present mainly in the calf and pectoral muscles ${ }^{7}$. Damage of myocardial fibers is also frequent and was first reported by Arean in $1962^{11}$, and afterwards that by de Brito et al. in $1987^{12}$. The pathogenesis of the muscular damage suggests a toxin-like action, explained by proteins secreted by leptospira or by proteins present in their membrane ${ }^{11-13}$.

Recently, immunohistochemistry findings in normal guinea pigs showed that two proteins, LipL32 and Lp25, from pathogenic Leptospira spp. can reach the skeletal muscle and induce lesions similar to those observed in leptospirosis. However, lesions in the group of animals inoculated with Lp25 were more diffuse and more accentuated than those found in the LipL32-inoculated group. Moreover, in experimental conditions, Lp25 was associated with acute kidney injury ${ }^{14}$.

LipL32 is the most expressed protein of leptospires $(32,190 \text { copies/cell })^{15,16}$. Although Lp25 protein is less expressed $\left(2,434\right.$ copies/cell) than LipL32 ${ }^{16}$, both are conserved membrane proteins in pathogenic species of leptospires, recognized by sera of patients in the convalescent phase of infection ${ }^{14-17}$ However, the role of these proteins in the pathogenesis of the disease remains unknown $^{18,19}$.

The present study was carried out with skeletal and heart muscle samples of fatal leptospirosis cases in an attempt to detect the presence of Lp25 and LipL32 in these tissues.

\section{MATERIAL AND METHODS}

\section{Patient samples}

This was a retrospective study on fatal leptospirosis cases admitted to different hospitals in Sao Paulo State, Brazil, during the years 2009-11, 2015 and 2016. Fragments of liver, kidney, and calf skeletal muscle obtained from twelve autopsied patients underwent histological analyses. In six of them, myocardium samples were also analyzed. The autopsies were complete and performed by different pathology laboratories in Sao Paulo after the family consent. Clinical data are in Table 1. Most patients were men $(83.33 \%)$ with a mean age of 46 years. All of them died between 4 and 8 days after admission with the clinical diagnosis of leptospirosis. The serodiagnosis of selected cases was incomplete due to the short time interval between patients' hospitalization and death. Only five patients presented with positive results in either ELISA-IgM and/or Microscopic Agglutination Test (MAT) (Table 1). Macroscopic autopsy findings in all patients were highly suggestive of severe leptospirosis, including jaundice, hemorrhage, hepatomegaly and splenomegaly.

\section{Ethics approval}

This retrospective study was approved by the Ethical Committee and Research Board of the Adolfo Lutz Institution, process number $\mathrm{N}^{\circ}$ 1928/2010 and 0017D/2010. Autopsies were performed after the written informed consent was obtained from the next of kin and all patients were anonymized.

\section{Antibodies}

Primary antibodies (Table 2) were produced in previous studies $^{14,17,20}$. Briefly, anti-Leptospira ${ }^{20}$, anti-Lp2 $5^{14}$ and anti-LipL $32^{17}$ were prepared by the hyper immunization of rabbits with a cellular suspension of Leptospira interrogans serovar Icterohaemorrhagiae strain R192, or with recombinant purified Lp25 or LipL32 proteins, respectively. The anti-Leptospira (anti-L) serum was used in the immunohistochemistry procedures to characterize the pathological features of leptospirosis in liver, kidney and muscular samples. The anti-Lp25 and anti-LipL32 were chosen in this study due to their ability to induce muscular lesions in guinea pigs, as previously published by our group ${ }^{14}$.

\section{Histopathological and immunohistochemistry (IHC)} procedures

Tissue fragments collected at the time of autopsies were fixed in $10 \%$ buffered formalin, embedded in paraffin and cut in 3-4 $\mu \mathrm{m}$ thick sections. Sections for morphological analyses were hematoxylin and eosin (H\&E) and Gomori trichrome-stained ${ }^{21}$. Immunohistochemistry (IHC) procedures were performed on $3 \mu \mathrm{m}$ tissue sections fixed in silane-treated slides. Prior to specific antibody incubation, slides with tissue sections were subjected to antigen retrieval in a pressure cooker using $10 \mathrm{mM}$ citrate buffer for $3 \mathrm{~min}\left(120^{\circ} \mathrm{C}, \mathrm{pH}\right.$ 6.0) followed by incubation with 3\% hydrogen peroxide solution in order to extinguish unspecific peroxidase activity. Tissue sections were then 
Table 1 - Demographic, clinical and laboratory data of patients with leptospirosis.

\begin{tabular}{|c|c|c|c|c|c|}
\hline Case $\mathrm{N}^{\circ}$ & Age $(y) /$ sex & Clinical data & $\begin{array}{l}\text { ELISA IgM } \\
\text { OD value } \\
\text { (cut-off) }\end{array}$ & $\begin{array}{c}\text { MAT } \\
\text { Serovar (title) }\end{array}$ & Samples \\
\hline$\# 1$ & $34 / \mathrm{M}$ & $\begin{array}{l}\text { Fever, jaundice, muscular } \\
\text { pain, vomiting }\end{array}$ & ND & ND & $\mathrm{m} / \mathrm{h}$ \\
\hline \#2 & $54 / \mathrm{M}$ & NA & $\begin{array}{c}\text { NR } \\
0.170(0.195)\end{array}$ & Copenhageni (1/400) & $\mathrm{m}$ \\
\hline \#3 & $53 / F$ & $\begin{array}{c}\text { Jaundice, hemoperitoneum, } \\
\text { obesity }\end{array}$ & $\begin{array}{c}N R \\
0.055(0.191)\end{array}$ & $\begin{array}{l}\text { Copenhageni Cynopteri } \\
(1 / 100)\end{array}$ & $\mathrm{m}$ \\
\hline$\# 4$ & $28 / \mathrm{M}$ & Fever, jaundice, diarrhea & ND & ND & $\mathrm{m}$ \\
\hline$\# 5$ & $38 / \mathrm{M}$ & $\begin{array}{l}\text { Jaundice, ascitis, pulmonary } \\
\text { hemorrhage }\end{array}$ & $\begin{array}{c}R \\
0.78(0.32)\end{array}$ & $\begin{array}{c}\text { Copenhageni } \\
\text { Icterohaemorrhagiae } \\
(1 / 400)\end{array}$ & $\mathrm{m} / \mathrm{h}$ \\
\hline$\# 6$ & $60 / \mathrm{M}$ & $\begin{array}{c}\text { Jaundice, pulmonary edema, } \\
\text { pleural effusion }\end{array}$ & ND & ND & $\mathrm{m}$ \\
\hline$\# 7$ & $62 / \mathrm{M}$ & $\begin{array}{l}\text { Jaundice, muscular pain, } \\
\text { renal failure }\end{array}$ & $\begin{array}{c}\text { NR } \\
0.10(1.10)\end{array}$ & ND & $\mathrm{m}$ \\
\hline \#8 & $60 / \mathrm{M}$ & $\begin{array}{l}\text { Fever, jaundice, muscular } \\
\text { pain, arrhythmia }\end{array}$ & ND & ND & $\mathrm{m} / \mathrm{h}$ \\
\hline$\# 9$ & $40 / \mathrm{M}$ & $\begin{array}{l}\text { Jaundice, pulmonary } \\
\text { hemorrhage }\end{array}$ & ND & ND & $\mathrm{m} / \mathrm{h}$ \\
\hline$\# 10$ & $30 / \mathrm{M}$ & NA & $\begin{array}{c}\mathrm{R} \\
2.4(1.1) \\
\end{array}$ & ND & $\mathrm{m} / \mathrm{h}$ \\
\hline$\# 11$ & $47 / F$ & Jaundice, muscular pain & ND & ND & $\mathrm{m} / \mathrm{h}$ \\
\hline$\# 12$ & $47 / M$ & Jaundice & ND & $\begin{array}{l}\text { Copenhageni } \\
(1 / 1,600)\end{array}$ & $\mathrm{m}$ \\
\hline
\end{tabular}

$\mathrm{M}$ = skeletal muscle sample; $\mathrm{h}$ = heart sample; OD = optical density; MAT = Microscopic Agglutination Test; ND = not determined; $\mathrm{NA}=$ none available; $\mathrm{NR}=$ non-reagent; $\mathrm{R}$ = reagent.

Table 2 - Antibody information.

\begin{tabular}{lcc}
\hline Antigen & Source & $\begin{array}{c}\text { Dilution in } \\
\text { IHC }\end{array}$ \\
\hline Leptospira (anti-L) & polyclonal rabbit & $1: 30,000$ \\
Lp25 protein (anti-Lp25) & polyclonal rabbit & $1: 4,000$ \\
LipL32 protein (anti-LipL32) & polyclonal rabbit & $1: 2,000$ \\
\hline
\end{tabular}

incubated overnight $\left(4{ }^{\circ} \mathrm{C}\right)$ with the primary antibodies shown in Table 2. Signal amplification with anti-L antibody was achieved by alkaline phosphatase (AP) conjugated polymer followed by chromogenic Fast Red revelation (red color) (MACH4 ${ }^{\mathrm{TM}}$ Universal AP Polymer Kit and WARP RED $^{\mathrm{TM}}$ chromogen kit (Biocare Medical, Concord, USA).

Immunostaining for Lp25 and LipL32 was achieved by using a horseradish peroxidase (HRP) conjugated polymer detection system (REVEAL Biotin-Free Polyvalent, Spring Bioscience Corp., USA) and color visualization (brown) developed by diaminobenzidine (Sigma-Aldrich, St. Louis, MO, USA).

\section{Histological and IHC analyses}

Histological muscular lesions were graded on a scale from 0 to 3: (0) normal (without lesions), (1) mild (presence of individual hyaline contraction change and focal interstitial reactivity), (2) moderate (necrosis of isolated muscle fibers, focal lesions of fibers and mild interstitial inflammatory infiltrate) and (3) severe (presence of extensive necrosis, multiple lesions of individual fibers and more intense interstitial inflammatory infiltrate). Immunoreactivity to leptospiral antigens was considered positive in muscle samples when small dots were noted in the cytoplasm of muscle fibers, interstitial macrophages or endothelial cells $^{14,22}$. The immunostaining observed with anti-Lp25 and anti-LipL32 was considered positive in muscle cells when finely granular antigen deposits partially delineated the sarcolemma and occasionally spread to the cytoplasm bellow, as previously documented ${ }^{14}$. Semiquantitative IHC analyses were performed as described by Meyerholz et al. ${ }^{23}$, considering the incidence of dots or antigen deposits stained in the cells. An ordinal IHC score of 0 to 3 was attributed 
to each specimen, as follows: (0): no staining; (1): weak; (2): moderate and (3): strong immunoreactivity.

\section{IHC controls}

In order to check nonspecific binding of secondary antibodies, IHC procedures were performed without the primary antibody, and no staining was detected. As the positive controls, a guinea pig liver sample from an experimental Leptospira interrogans serovar Copenhageni infection was used with anti-L, and a guinea pig skeletal muscle sample from our previous experimental study ${ }^{14}$ was used with anti-Lp25 and anti-LipL32. A positive immunoreactivity was observed with all antibodies, as described above (IHC analyses). As negative controls, all antibodies were tested with normal human liver and heart samples (without histological lesions) and specimens collected from six non-leptospirosis patients (2 patients with meningococcal meningitis, 2 with yellow fever and 2 with Rocky Mountain spotted fever). All negative controls showed no immunoreactivity.

\section{RESULTS}

It was not possible to confirm the serological diagnosis of leptospirosis in all cases due to the short time interval between patients' hospitalization and death (Table 1). Usually, the microscopic agglutination test (MAT) and the enzyme-linked immunosorbent assay (ELISA-IgM) are less sensitive during the early stages of leptospirosis, so that histological and IHC analyses of kidney and liver samples, using anti-Leptospira (anti-L) primary antibody (Table 2), were performed to confirm the diagnosis. Results showed that all patients presented with typical histopathological features of leptospirosis. Kidney sections presented with acute tubular necrosis, cell edema and focal interstitial nephritis. Moreover, areas of liver cells disruption were observed in the sections (Figure 1). These data support

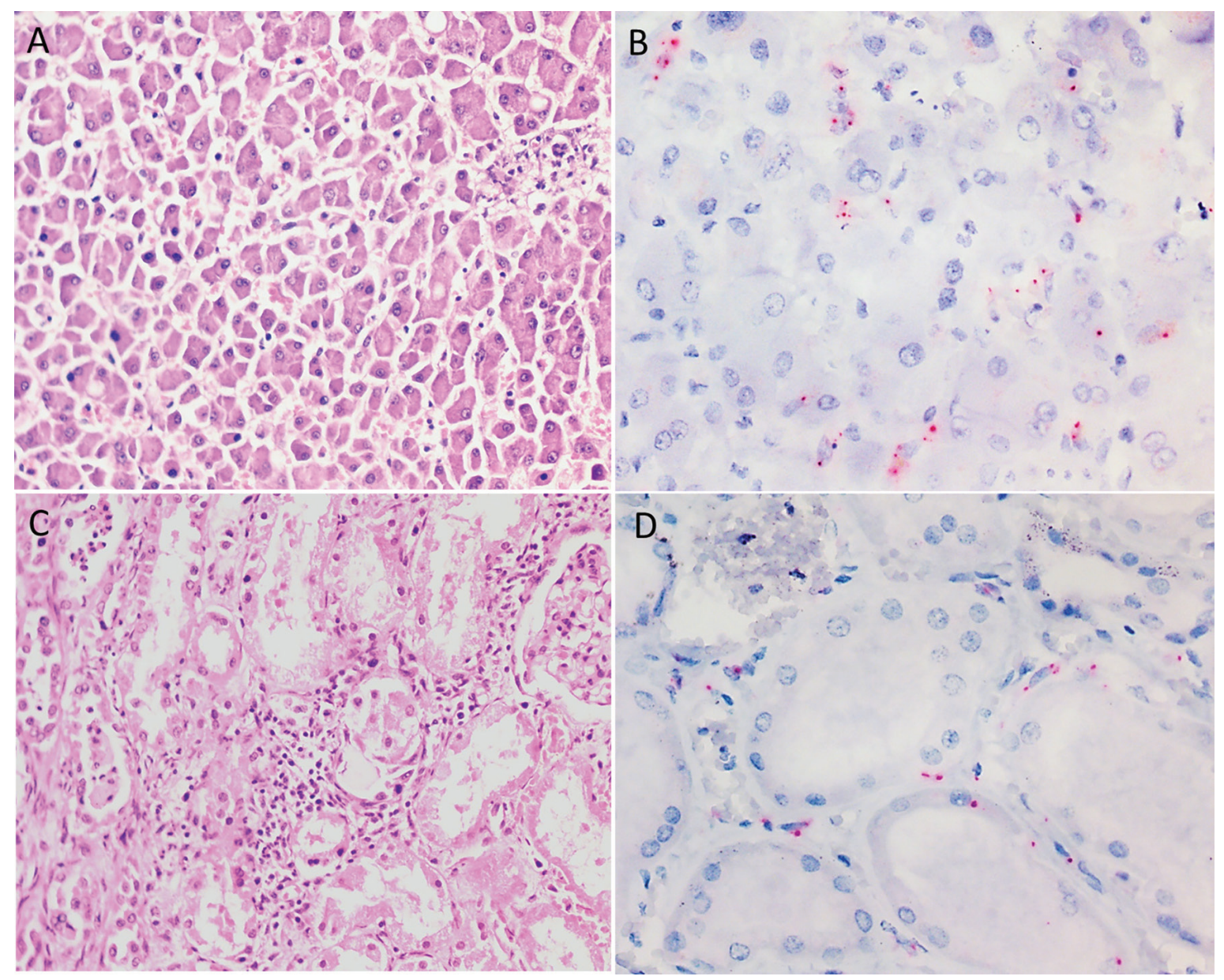

Figure 1 - Immunohistochemistry and histology analyses of liver (A/B, \#4) and kidney samples (C/D, \#8). A) H\&E staining showing remarkable liver cells disruption with poor inflammatory infiltrate in the portal space (200 X); B) Leptospira-immunohistochemistry showing small leptospira antigens as small dots inside Kupffer cells (400 X); C) H\&E staining showing interstitial nephritis with scarce inflammatory infiltrate mainly composed of mononuclear cells (200 X); D) Leptospira-immunohistochemistry showing small leptospira antigens as small dots in tubular cells and interstitium (400 X). 
the clinical diagnosis of severe leptospirosis in all selected cases.

Histological and IHC analyses of skeletal and cardiac muscle sections used the anti-L, anti-Lp25 and anti-LipL32 primary antibodies. As shown in Table 3 and Figure 2, skeletal muscles were involved in all cases with different degrees of severity. The histological findings consisted of isolated or small groups of muscle fiber lesions, which may exhibit loss of striation and hyaline cytoplasmic changes: small cytoplasmic vacuoles, hypercontraction of isolated fibers that may progress to necrosis with lumps of cytoplasmic hyaline material and eventually to phagocytosis. The dye changes of cytoplasmic myofibrils were easily observed by usual staining (H\&E) (Figure 2A), but were better seen by the Gomori trichrome dye as pale cells ("ghost cells") (Figures 2C and 2D). The most evident aspect was necrosis of isolated fibers or of small groups, seen in all cases. In 7/12 cases, the necrosis of isolated fibers was considered more extensive and more frequent (Table 3). Only mild inflammatory infiltrates were seen in skeletal muscle, particularly around necrotic macrophages and lymphocytes (10/12). Inflammatory infiltrates were not intense in any of the cases. In one case, it was moderate $(1 / 12 ; \# 4)$ and in another, no inflammation was detected (\#9). Neutrophils and interstitial hemorrhage were not seen. There was neither a wide range of muscle fiber sizes (atrophy/hypertrophy) nor muscle fibrosis.

Leptospira (L) antigens were detected by IHC in all skeletal muscle samples, usually within macrophages, interstitium and inside muscle fibers as dot deposits (Table 3, Figure 2B). In one case, they were very frequent, especially in the interstitium (\#11) and in another case, L antigens were also seen in endothelial cells (\#2).

IHC with antibodies anti-LipL32 and anti-Lp25 were positive in all skeletal muscle samples (Table 3, Figures 2E and 2F). Multifocal antigenic granular deposits were seen partially circumscribing the sarcolemma of isolate muscular fibers or in small groups. Occasionally they spread to the cytoplasm and sometimes they were present in necrotic cells.

The intensity of anti-Lp25 detection was moderate or strong (2+ or $3+)$ in 10 cases, meanwhile, immunostaining with anti-LipL32 was considered moderate in only three cases, and in none of them it was strong (Table 3 ).

In heart samples, lesions were not as evident as in skeletal muscles, as shown in Table 4 and Figure 3. Remarkable findings were hypercontraction of isolated fibers (mild or moderate, 5/6) and interstitial inflammatory infiltrates in myocardium consisting of macrophages and lymphocytes (6/6) (Table 4). Likewise, in skeletal muscle samples, neutrophils were not present. A similar inflammatory infiltrate was present in the endocardium in three cases (\#1; \#5; \#11), and in the pericardium of case \#1 (pancarditis). Sometimes the infiltrate was more frequent around intramyocardial coronary blood vessels, resembling Aschoff's nodules (\#5, \#9). Unlike skeletal muscle samples, neither fiber necrosis nor "ghost cells" were seen even with Gomori staining (Figure 3).

Table 3 - Histological and immunohistochemistry (IHC) scores of skeletal muscle samples.

\begin{tabular}{|c|c|c|c|c|c|c|c|}
\hline \multirow{2}{*}{ Case $^{\mathrm{a}} \mathrm{N}^{\mathrm{O}}$} & \multicolumn{4}{|c|}{ Histological score ${ }^{\mathrm{b}}$} & \multicolumn{3}{|c|}{ IHC score ${ }^{c}$} \\
\hline & Hyaline & Ghost cell & Necrosis & Inflammation & Anti-L & Anti-LipL32 & Anti-Lp25 \\
\hline$\# 1$ & $3+$ & $2+$ & $3+$ & $1+$ & $2+$ & $1+$ & $3+$ \\
\hline \#2 & $2+$ & $3+$ & $3+$ & $1+$ & $3+$ & $1+$ & $3+$ \\
\hline$\# 3$ & $2+$ & $2+$ & $2+$ & $1+$ & $1+$ & $1+$ & $2+$ \\
\hline$\# 4$ & $3+$ & $3+$ & $3+$ & $2+$ & $1+$ & $1+$ & $3+$ \\
\hline \#5 & $2+$ & $2+$ & $3+$ & $1+$ & $1+$ & $2+$ & $3+$ \\
\hline$\# 6$ & $1+$ & $1+$ & $2+$ & $1+$ & $1+$ & $2+$ & $1+$ \\
\hline$\# 7$ & $2+$ & $1+$ & $1+$ & $1+$ & $1+$ & $1+$ & $3+$ \\
\hline \#8 & $3+$ & $2+$ & $3+$ & $1+$ & $1+$ & $1+$ & $2+$ \\
\hline$\# 9$ & $2+$ & $2+$ & $1+$ & $0+$ & $1+$ & $1+$ & $1+$ \\
\hline$\# 10$ & $1+$ & $1+$ & $2+$ & $1+$ & $1+$ & $1+$ & $2+$ \\
\hline$\# 11$ & $2+$ & $1+$ & $3+$ & $1+$ & $3+$ & $2+$ & $3+$ \\
\hline \#12 & $1+$ & $2+$ & $3+$ & $1+$ & $1+$ & $1+$ & $3+$ \\
\hline
\end{tabular}

aNumbers correspond to the identification of each patient as described in Table 1; bSkeletal musclesamples were stained with $\mathrm{H} \& \mathrm{E}$ and trichrome Gomori. Muscular lesions were graded as described in Material and Methods; ' Skeletal muscle samples were submitted to IHC with anti-L, anti-Lp25 and anti-LipL32 antibodies. Semiquantitative analyses were performed as described in Material and Methods. 

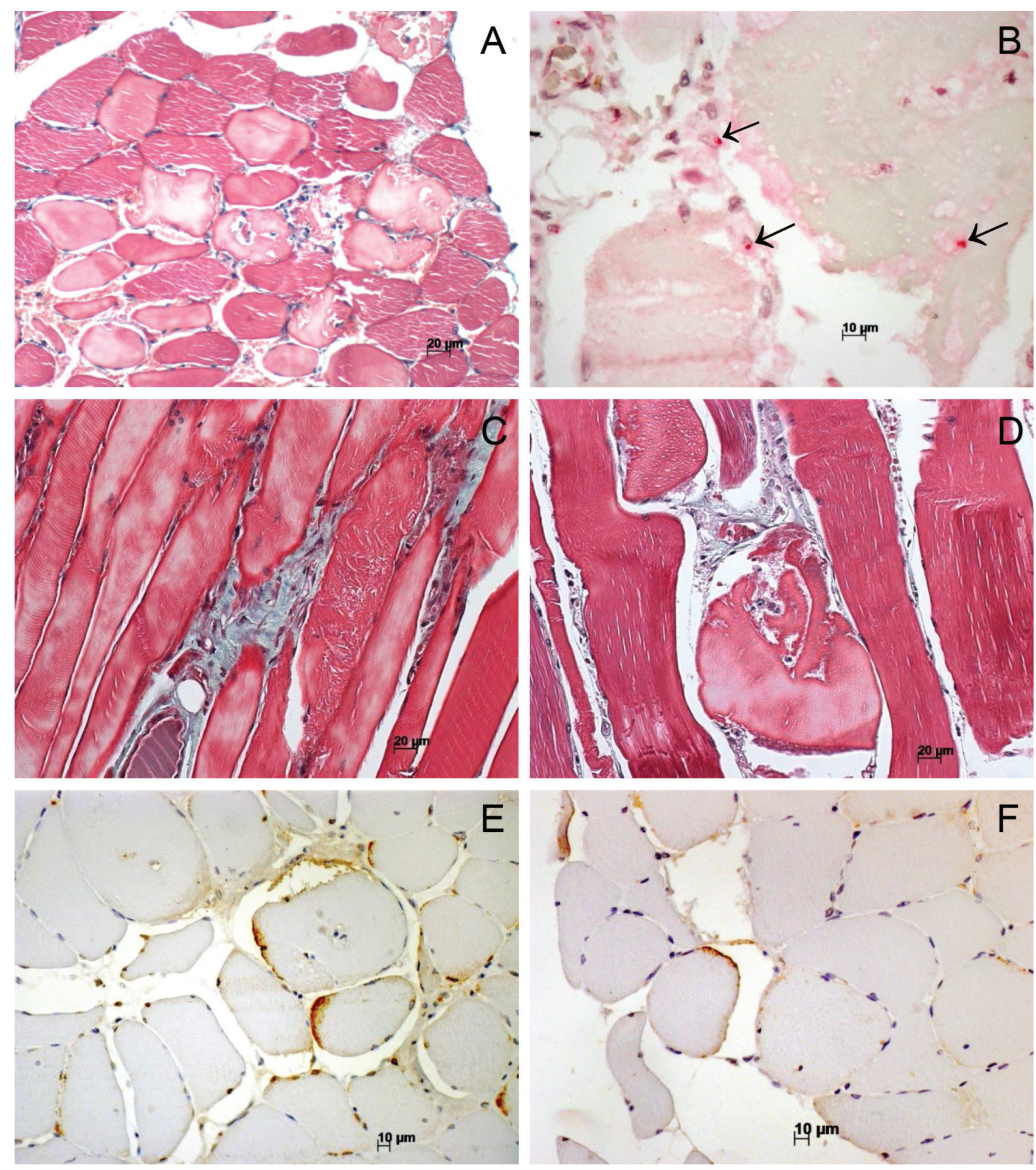

Figure 2 - Immunohistochemistry and histology analyses of skeletal muscle samples. A) H\&E staining showing fiber muscle necrosis and "ghost cells" (clear cells) with scarce interstitial inflammatory infiltrate, mainly composed of mononuclear cells (\#4); B) Leptospira-IHC showing small leptospira antigens as small red dots indicated by arrows, inside necrotic muscle fiber and also in the interstitium (\#11); C) Gomori staining showing "ghost cells" and partially necrotic fibers; D) A necrotic muscle fiber in detail, Gomori staining; E) Lp25-IHC showing granular antigen deposits on the sarcolemma and peripheral cytoplasm (\#7); F) LipL32-IHC showing similar sarcolemma antigen deposits. These deposits are scarcer when compared to Lp25 (\#7).

Leptospira antigens were present in all cases (6/6) in the interstitium, muscle fibers and sometimes in endothelial cells (2/6) (\#1,\#5) (Table 4 and Figure 3). Immunohistochemistry with Lip25 and LpL32 was weaker in cardiac muscle than in skeletal muscle, but immunostaining was similar between them. The antigen Lp25 was positive in four cases (4/6) and 
Table 4 - Histological and immunohistochemistry (IHC) scores of heart muscle samples.

\begin{tabular}{|c|c|c|c|c|c|c|c|}
\hline \multirow{2}{*}{ Case $^{a} \mathrm{~N}^{\circ}$} & \multicolumn{4}{|c|}{ Histological score ${ }^{b}$} & \multicolumn{3}{|c|}{$\mathrm{IHC}$ score $^{\mathrm{c}}$} \\
\hline & Hyaline & Ghost cell & Necrosis & Inflammation & Anti-L & Anti-LipL32 & Anti-Lp25 \\
\hline$\# 1$ & $2+$ & $0+$ & $0+$ & $3+$ & $3+$ & $1+$ & $3+$ \\
\hline \#5 & $2+$ & $0+$ & $0+$ & $2+$ & $1+$ & $1+$ & $1+$ \\
\hline$\# 8$ & $1+$ & $0+$ & $0+$ & $1+$ & $1+$ & $0+$ & $0+$ \\
\hline$\# 9$ & $1+$ & $0+$ & $0+$ & $2+$ & $1+$ & $1+$ & $0+$ \\
\hline$\# 10$ & $0+$ & $0+$ & $0+$ & $1+$ & $1+$ & $1+$ & $1+$ \\
\hline \#11 & $2+$ & $0+$ & $0+$ & $2+$ & $2+$ & $1+$ & $2+$ \\
\hline
\end{tabular}

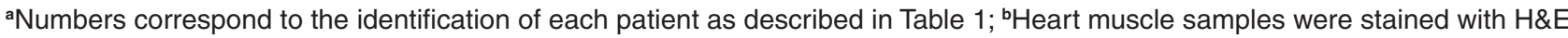
and trichrome Gomori. Muscular lesions were graded as described in Material and Methods; ${ }^{c H e a r t ~ m u s c l e ~ s a m p l e s ~ w e r e ~ s u b m i t t e d ~}$ to $\mathrm{IHC}$ analysis using anti-L, anti-Lp25 and anti-LipL32 antibodies. Semiquantitative analyses were performed as described in Material and Methods.
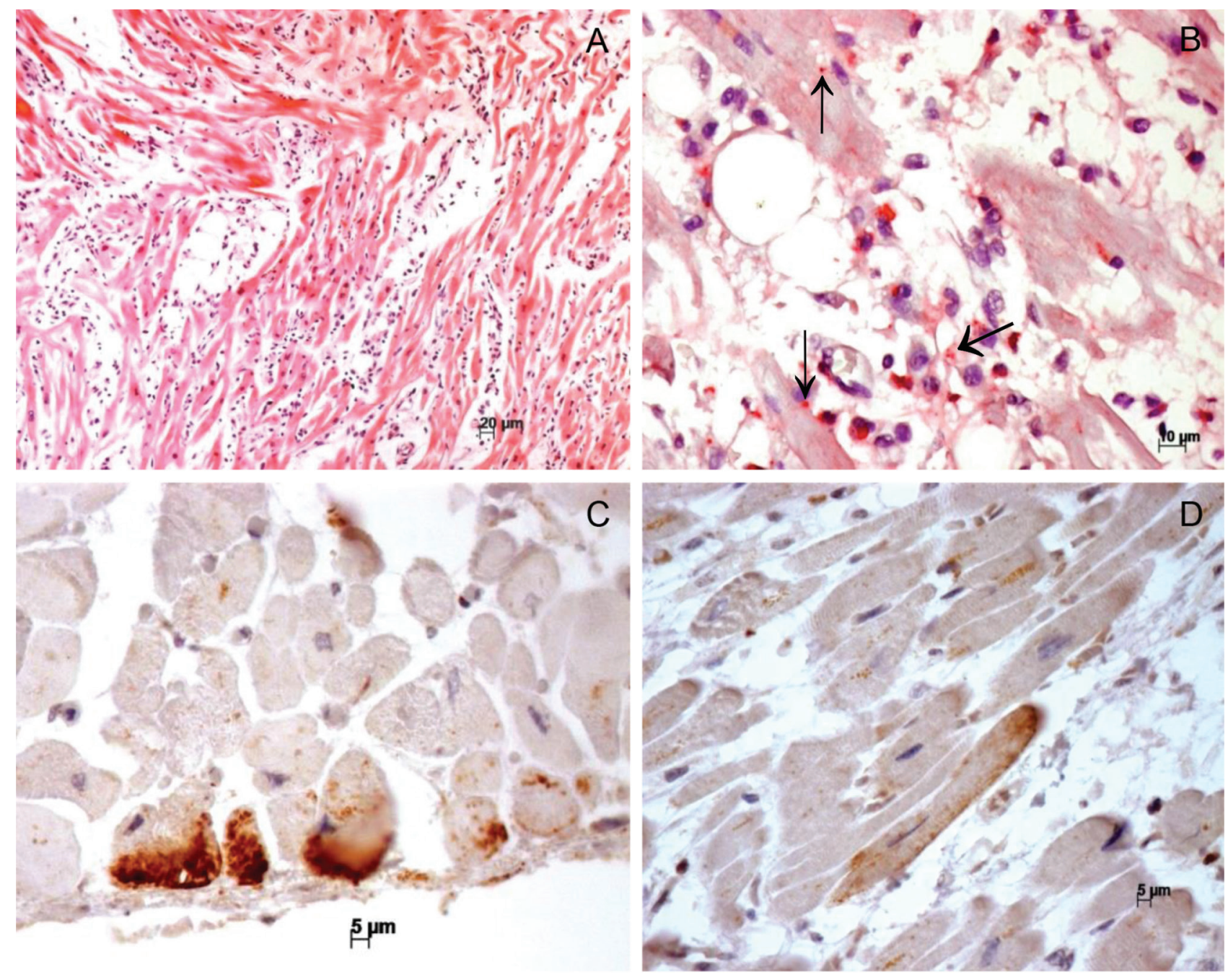

Figure 3 - Immunohistochemistry and histology analyses of heart muscle samples. A) H\&E staining showing myocarditis and hyaline contraction of heart cells (\#1); B) Leptospira-IHC showing red dots of leptospira antigens indicated by arrows, in the interstitium and the cytoplasm of macrophages and cardiac myocytes (\#1); C) Lp25-IHC showing brownish granules deposits in the cytoplasm and on the membrane in a small group of cardiac myocytes (\#11); D) LipL32-IHC showing deposits of antigen in the cytoplasm and on the membrane of an isolate cardiac myocyte (\#11). 
the antigen LipL32 was weakly marked in isolated and focal fibers (5/6) (Table 4 and Figure 3).

In two cases (\#1 and \#11), skeletal muscles and heart lesions were more accentuated marked. The skeletal muscle exhibited "ghost cells" and remarkable necrosis of muscle fibers with scarce inflammatory infiltrate. LipL32 and Lp25 antigens were more easily detected in these samples (Figures 2 and 3). In heart samples, the inflammatory infiltrate was more evident in the myocardium and endocardium and LipL32 and Lp25 antigens were more evident as well (Figure 3).

\section{DISCUSSION}

In severe manifestations of leptospirosis, the liver, lungs and kidneys are the main affected organs resulting in jaundice, pulmonary hemorrhage and acute kidney injury, respectively ${ }^{1,2}$. Previous autopsy reports have shown that lesions found in fatal cases of leptospirosis are not limited to these organs ${ }^{11-13}$. Cardiac and striated muscle injuries have also been reported $\mathrm{d}^{5,11,12,22,24}$. However, the pathophysiology of these lesions is not fully understood.

In the present study, the histological findings in skeletal muscle were the same as the ones described by Jeghers et al. ${ }^{5}$ in 1935 in gastrocnemius muscle and afterwards by Sheldon ${ }^{24}$ and Uip et al. ${ }^{22}$. Different aspects of muscle fiber necrosis were frequent, with minimum inflammatory infiltrate in most cases. It seems that the process began with loss of isolated fibers striation, hyalinization and swelling, progressing to necrosis. Only when the round lumps of hyaline material in the cytoplasm appeared (definite necrosis), a scarce inflammatory infiltrate composed of macrophages and lymphocytes was evident. Neutrophils and other polymorphonuclear cells were not present. Therefore, the process seems to be necroticdegenerative and not inflammatory. Leptospiral antigens were frequently observed in the skeletal muscle samples by immunohistochemistry ${ }^{12,22}$.

For several years, the important role of rhabdomyolysis in the pathogenesis of leptospirosis was neglected, in spite of myalgia being frequently the first symptom noticed by the patient ${ }^{6}$. Considering the extensive necrosis that was detected in calf muscle and probably also in pectoral and abdominal muscles, as observed by Solbrig et al. ${ }^{25}$, we imagine a massive release of intracellular enzymes and myoglobin in the bloodstream in a short period of time, the same situation found in acute muscle trauma. Rhabdomyolysis is known as an important factor that can induce acute kidney injury in leptospirosis, as many authors have suggested ${ }^{7,25,26}$. An association between the creatinine phosphokinase level and the maximum serum creatinine level was demonstrated in patients with severe forms of leptospirosis and high serum potassium levels ${ }^{25}$.

On the other hand, the histological features seen in cardiac muscles were different from the ones seen in skeletal muscles. The interstitial inflammatory infiltrate was much more important than necrosis, which was focal and limited to loss of striation and hyalinization of isolated fibers. It seems that the inflammatory infiltrate was independent of necrosis. Cytoplasm edema and lumps of cytoplasmic hyaline material were not identified in our cases. Sometimes endocardium, pericardium and intramyocardial vessels were also compromised by inflammatory infiltrates, as previously documented ${ }^{9}$. Leptospira antigens were easily demonstrated in myocytes, interstitium and endothelial cells. From a clinical point of view, myocarditis has important consequences in severe leptospirosis ${ }^{27,28}$. It seems that the cardiac muscle was involved in the course of septicemia, through hematogenous dissemination ${ }^{29,30}$.

The Lp25 and LipL32 proteins were demonstrated by immunohistochemistry on the muscle cell membrane, underlying the cytoplasm in skeletal muscle and focally in cardiac samples of fatal human cases. Both had the same IHC aspect, similarly to what was described in an experimental mode ${ }^{14}$. It is noteworthy that, unlike previous experimental studies, we deal with patients who died due to leptospirosis. In the previous report, we evaluated the effect of LipL32 and Lp25 proteins on renal function of normal guinea pigs ${ }^{14}$. Only Lp25 was associated with oliguric acute kidney injuries and hyperkalemia induced by rhabdomyolysis. Interestingly, both proteins were able to reach the skeletal muscles and produce lesions. However, the muscular lesions observed in the group inoculated with Lp25 were more diffuse and more intense than those seen with LipL32 presenting with the inflammatory infiltrates and areas of necrosis characterized by "ghost cells"14.

It has been reported that some bacterial infections might cause rhabdomyolysis ${ }^{8,31}$, including Legionella species $^{2}$, which are the most common one, followed by Salmonella $\mathrm{spp}^{33}$, Streptococci ${ }^{34}$, Leptospira $\mathrm{spp}^{7}$, Staphylococcus aureus $^{35}$, among others. The mechanisms of rhabdomyolysis induction after bacterial infections are not completely elicited $^{8,31}$. There is evidence that these pathogens may cause injury either by the direct invasion of muscles or by the production of toxins ${ }^{31}$. Salmonella and Streptococcus species are able to invade muscle cells, and to suppress glycolytic and oxidative enzymes, leading to an extensive muscle necrosis ${ }^{31,34}$. In contrast, other bacteria, such as Legionella $\mathrm{spp}^{32}$ and Clostridium perfringens, are not able to invade muscle cells, but they may secret toxins that induce myonecrosis ${ }^{36}$. The same could happen in the leptospira infection. Previous studies have suggested that leptospirosis 
is a disease of the cell membrane as was demonstrated by leptospira antigen deposits on the cell membrane, and by the loss and/or alteration of cadherin expression. In this context, the pathogenesis of muscular damage suggests a toxin-like action of leptospira proteins, possibly as an important factor in the mechanism of the disease ${ }^{12,13}$.

\section{CONCLUSION}

The pathophysiology of leptospirosis is not yet clearly understood. Direct invasion of muscle cells by spirochetes, secondary immune response, injury of vascular endothelial cells and a possible leptospira cellular toxin have been frequently considered. Until now, this toxin has not been characterized. It is possible that bacterial proteins and/or toxic cellular components could initially act on the muscle cell membrane with dramatic consequences to the host. In this context, both membrane proteins, Lp25 and LipL32, could be important factors in the pathogenesis of leptospirosis.

\section{ACKNOWLEDGMENTS}

The authors thank Mr. Brian F. Weymouth for providing editorial assistance.

\section{FUNDING}

This study was funded by Fundação de Amparo à Pesquisa no Estado de São Paulo (FAPESP 2019/00546-0) and São Paulo State Health Secretary - Disease Control Coordination (FESIMA-SES-PRC2019/03773). ACS was supported by Conselho Nacional de Desenvolvimento Científico e Tecnológico (CNPq), grant $\left.\mathrm{N}^{\circ} 302599 / 2018-5\right)$. The funders had no role in the study design, data collection and analysis, decision to publish or preparation of the manuscript.

\section{REFERENCES}

1. Bharti AR, Nally JE, Ricaldi JN, Matthias MA, Diaz MM, Lovett MA, et al. Leptospirosis: a zoonotic disease of global importance. Lancet Infect Dis. 2003;3: 757-71.

2. Haake DA, Levett PN. Leptospirosis in humans. In: Adler B, editor. Leptospira and leptospirosis. Berlin: Springer-Verlag; 2015. p.65-91.

3. McBride AJ, Athanazio DA, Reis MG, Ko AI. Leptospirosis. Curr Opin Infect Dis. 2005;18:376-86.

4. Spichler AS, Vilaça PJ, Athanazio DA, Albuquerque JO, Buzzar M, Castro B, et al. Predictors of lethality in severe leptospirosis in urban Brazil. Am J Trop Med Hyg. 2008;79:911-4.

5. Jeghers HJ, Houghton JB, Foley JA. Weil's disease: report of a case with postmortem observations and review of recent literature. Arch Pathol. 1935;20:447-76.

6. Andrade L, Daher EF, Seguro AC. Leptospiral nephropathy. Semin Nephrol. 2008;28:383-94.

7. Martinelli R, Luna MA, Rocha H. Is rhabdomyolysis an additional factor in the pathogenesis of acute renal failure in leptospirosis? Rev Inst Med Trop São Paulo. 1994;36:111-4.

8. Khan FY. Rhabdomyolysis: a review of the literature. Neth J Med. 2009;67:272-83.

9. Dubowitz V, Sewry C, Oldfors A. Muscle biopsy: a practical approach. $4^{\text {th }}$ ed Philadelphia: Saunders; 2013. p.541.

10. Daher EF, Abreu KL, Silva Junior GB. Insuficiência renal aguda associada à leptospirose. J Bras Nefrol. 2010;32:408-15.

11. Arean VM. The pathologic anatomy and pathogenesis of fatal human leptospirosis (Weil's disease). Am J Pathol. 1962;40:393-423.

12. de Brito T, Morais CF, Yasuda PH, Lancellotti CP, HoshinoShimizu S, Yamashiro E, et al. Cardiovascular involvement in human and experimental leptospirosis: pathologic findings and immunohistochemical detection of leptospiral antigen. Ann Trop Med Parasitol. 1987;81:207-14.

13. de Brito T, Silva AM, Abreu PA. Pathology and pathogenesis of human leptospirosis: a commented review. Rev Inst Med Trop São Paulo. 2018;60:e23.

14. Abreu PA, Seguro AC, Canale D, Silva AM, Matos LR, Gotti TB, et al. Lp25 membrane protein from pathogenic Leptospira spp is associated with rhabdomyolysis and acute oliguric acute kidney injury in a guinea pig model of leptospirosis. PLoS Negl Trop Dis. 2017;11:e0005615.

15. Pinne M, Haake DA. LipL32 is a subsurface lipoprotein of Leptospira interrogans: presentation of new dta and reevaluation of previous studies. PLoS One. 2013;8:e51025.

16. Malmström J, Beck M, Schmidt A, Lange V, Deutsch EW, Aebersold R. Proteome-wide cellular protein concentrations of the human pathogen Leptospira interrogans. Nature. 2009;460:762-5.

17. Monaris D, Sbrogio-Almeida ME, Dib CC, Canhamero TA, Morais ZM, Vasconcellos SA, et al. Protective immunity and reduced renal colonization induced by vaccines containing recombinant Leptospira interrogans outer membrane proteins and flagellin adjuvant. Clin Vaccine Immunol. 2015;22:965-73.

18. Murray GL. The lipoprotein LipL32, an enigma of leptospiral pathology. Vet Microbiol. 2013;162:305-14.

19. Fouts DE, Matthias MA, Adhikarla H, Adler B, Amorim-Santos L, Berg DE, et al. What makes a bacterial species pathogenic? Comparative genomic analysis of the genus Leptospira. PLoS Negl Trop Dis. 2016;10:e0004403.

20. Alves VA, Yasuda PH, Yamashiro EH, Santos RT, Yamamoto L, de Brito T. An immunohistochemical assay to localize leptospires in tissue specimens. Rev Inst Med Trop Sao Paulo. 1986;28:170-3. 
21. Gridley MF. Manual of histologic and special staining technics. Washington: Armed Forces Institute of Pathology; 1957.

22. Uip DE, Amato Neto V, Duarte MS. Diagnóstico precoce da leptospirose por demonstração de antígenos através de exame imunohistoquímico em músculo da panturrilha. Inst Med Trop Sao Paulo. 1992;34:375-81.

23. Meyerholz DK, Beck AP. Principles and approaches for reproducible scoring of tissue stains in research. Lab Invest. 2018;98:844-55.

24. Sheldon WH. Lesions of muscle in spirochetal jaundice (Weil's disease, spirochetosis icterohemorrhagica). Arch Intern Med (Chic). 1945;75:119-24.

25. Solbrig MV, Sher JH, Kula RW. Rhabdomyolysis in leptospirosis (Weil's disease). J Infect Dis. 1987;156:692-3.

26. Libório AB. Can rhabdomyolysis be the only cause of acute renal failure in leptospirosis? Nephrol Dial Transplant. 2005;20:2580-1.

27. Jayathilaka PG, Mendis AS, Perera MH, Damsiri HM, Gunaratne AV, Agampodi SB. An outbreak of leptospirosis with predominant cardiac involvement: a case series. BMC Infect Dis. 2019;19:265.

28. Shah K, Amonkar GP, Kamat RN, Deshpande JR. Cardiac findings in leptospirosis. J Clin Pathol. 2010;63:119-23.
29. Marotto PC, Nascimento CM, Eluf-Neto J, Marotto MS, Andrade L, Sztajnbok J, et al. Acute lung injury in leptospirosis: clinical and laboratory features, outcome, and factors associated with mortality. Clin Infect Dis. 1999;29:1561-3.

30. Leone O, Pieroni M, Rapezzi C, Olivotto I. The spectrum of myocarditis: from pathology to the clinics. Virchows Arch. 2019;475:279-301.

31. Viswerswaran P, Guntupalli J. Rhabdomyolysis. Crit Care Clin. 1999;15:415-28.

32. Erdogan H, Yilmaz A, Kal O, Erdogan A, Arslan H. Rhabdomyolysis-induced acute renal failure associated with legionnaires' disease. Scand J Urol Nephrol. 2006;40:345-6.

33. Khan FY, Al-Ani A, Ali HA. Typhoid rhabdomyolysis with acute renal failure and acute pancreatitis: a case report and review of the literature. Int J Infect Dis. 2009;13:e282-5.

34. Ojukwu IC, Newton DW, Luque AE, Kotb MY, Menegus M. Invasive Group C Streptococcus infection associated with rhabdomyolysis and disseminated intravascular coagulation in a previously healthy adult. Scand J Infect Dis. 2001;33:227-9.

35. Lannigan R, Austin TW, Vestrup J. Myositis and rhabdomyolysis due to Staphylococcus aureus septicemia. J Infect Dis. 1984;150:784.

36. Bryant AE, Stevens DL. Clostridial myonecrosis: new insights in pathogenesis and management. Curr Infect Dis Rep. 2010;12:383-91. 